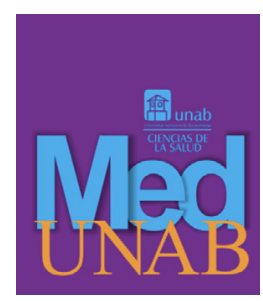

REVISTA DE LA FACULTAD

DE CIENCIAS DE LA SALUD

\title{
Percepción de los padres acerca del estado de salud y bienestar de sus hijos adolescentes de 15 a 18 años
}

Parents' perception of the state of health and wellbeing of their adolescent children aged 15 to 18 years

Percepção dos pais sobre o estado de saúde e bem-estar de seus filhos adolescentes de 15 a 18 anos

Mary Luz Jaimes-Valencia, Enf., Msc., PhD. ${ }^{1}$ (D), Yorlenis Saavedra-Rey, Enf. ${ }^{2}$ (D), Leidy Tatiana Rincón-Pabón, Enf. ${ }^{3}$ (D), John Freddy Arguello-Duarte, Enf., MSc. ${ }^{4}$ (D), Socorro Fajardo-Natez, Enf., Esp. ${ }^{5}$ (D), Blanca Piratoba-Hernández, Enf., MSc. ${ }^{6}$ (D)

1. Enfermera, Magíster en Enfermería, Doctora en Enfermería Práctica y Educación, Docente Titular, Programa de Enfermería, Universidad Autónoma de Bucaramanga, Bucaramanga, Colombia.

2. Enfermera, Hospital El Salvador de Ubaté, Ubaté, Colombia.

3. Enfermera, Hospital Universitario de Santander, Bucaramanga, Colombia.

4. Enfermero, Magíster en Neurociencias y biología del comportamiento, Docente Asistente, Programa de Enfermería, Universidad Autónoma de Bucaramanga, Bucaramanga, Colombia.

5. Enfermera, Especialista en Administración en Servicios de Salud, Docente Asistente, Programa de Enfermería, Universidad Autónoma de Bucaramanga, Bucaramanga, Colombia.

6. Enfermera, Magíster en Enfermería, Profesora Asistente. Facultad de Enfermería. Universidad Nacional de Colombia, Bogotá Colombia.

Correspondencia. Mary Luz Jaimes Valencia. Universidad Autónoma de Bucaramanga, Campus el Bosque. Email. mjaimes239@unab.edu.co

\section{INFORMACIÓN DEL ARTÍCULO:}

Artículo recibido: 08 de noviembre de 2019

Artículo aceptado: 03 de junio de 2021

DOI: https://doi.org/10.29375/01237047.3738

Cómo citar. Jaimes-Valencia ML, Saavedra-Rey Y, Rincón-Pabón LT, ArguelloDuarte JF, Fajardo-Natez S, Piratoba-Hernández B. Percepción de los padres acerca del estado de salud y bienestar de sus hijos adolescentes de 15 a 18 años. MedUNAB. 2021; 24(2): 203-219 doi: https://doi.org/10.29375/01237047.3738

\section{RESUMEN:}

Introducción. El término "autopercepción del estado de salud" se refiere a la información brindada por el individuo sobre su estado de salud de acuerdo con sus conocimientos e interpretaciones y, en otras ocasiones, dado por los 
padres o acudientes. El objetivo de este estudio es describir las percepciones que tienen los padres respecto al estado de salud y el bienestar de sus hijos escolarizados de 15 a 18 años. Metodología. Estudio cualitativo, con la técnica de grupo focal. Con participación de 10 padres de familia de adolescentes escolarizados entre 15 a 18 años de una institución educativa pública de la ciudad de Bucaramanga, Santander. Resultados: Se identificaron 11 categorías y 6 subcategorías. Dentro de las categorías a resaltar se encuentra la tecnología que, según los padres, presenta aspectos positivos y negativos puesto que afecta la salud en dimensiones como los hábitos alimenticios, las relaciones interpersonales, entre otros. Este componente es poco documentado en los estudios que se localizaron. Discusión: En las narrativas se identifican la espiritualidad y la tecnología como aspectos que afectan la salud de manera positiva y negativa coincidiendo con otros autores. Conclusiones: A través de las narrativas de los padres se logra identificar que la salud es multidimensional y que la afectan varios componentes, entre ellos los psicosociales, en especial durante la etapa de adolescencia de sus hijos.

Palabras claves:

Calidad de Vida; Adolescente; Percepción; Salud; Condiciones Sociales

\section{ABSTRACT}

Introduction. The term "self-perception of health status" refers to the information provided by the individual about their state of health according to their knowledge and interpretations and, on other occasions, provided by parents or guardians. The objective of this study is to describe the perceptions that parents have regarding the state of health and wellbeing of their children aged 15 to 18 years who attend school. Methodology. Qualitative study, with the focus group technique. With the participation of 10 parents of adolescents between 15 to 18 years of age who attend a public school in the city of Bucaramanga, Santander. Results. Eleven categories and six subcategories were identified. Among the categories to be highlighted is technology that, according to parents, has positive and negative aspects since it affects health in dimensions such as eating habits, interpersonal relationships, among others. This component is poorly documented in the studies that were located. Discussion: in the narratives, spirituality and technology are identified as aspects that affect health in a positive and negative way, coinciding with other authors. Conclusions. Through the narratives of the parents, it is possible to identify that health is multidimensional and that it is affected by various components, including psychosocial ones, especially during the adolescence stage of their children.

Keywords:

Quality of Life; Adolescent; Perception; Health; Social Conditions

\section{RESUMO}

Introdução. O termo "autopercepção do estado de saúde" refere-se às informações fornecidas pelo indivíduo sobre seu estado de saúde de acordo com seus conhecimentos e interpretações e, em outras ocasiões, fornecidas pelos pais ou responsáveis. O objetivo deste estudo é descrever a percepção que os pais têm sobre o estado de saúde e bem-estar de seus filhos na idade escolar de 15 a 18 anos. Metodologia. Estudo qualitativo, utilizando a técnica de grupo focal. Com a participação de 10 pais de adolescentes escolarizados entre 15 e 18 anos de uma instituição de ensino pública na cidade de Bucaramanga, Santander. Resultados. Foram identificadas 11 categorias e 6 subcategorias. Entre as categorias a serem destacadas está a tecnologia que, segundo os pais, apresenta aspectos positivos e negativos, pois afeta a saúde em dimensões como hábitos alimentares, relacionamento interpessoal, entre outras. Este componente está pouco documentado nos estudos localizados. Discussão. Nas narrativas, espiritualidade e tecnologia são identificados como aspectos que afetam a saúde de forma positiva e negativa, coincidindo com outros autores. Conclusões. Por meio das narrativas dos pais, é possível identificar que a saúde é multidimensional e é afetada por diversos componentes, inclusive psicossociais, principalmente na fase da adolescência dos filhos.

Palavras-chave:

Qualidade de Vida; Adolescente; Percepção; Saúde; Condições Sociais 


\section{Introducción}

El concepto de calidad de vida en adultos ha progresado en los últimos años, pero en niños y adolescentes es un campo de acción muy reciente. La OMS define la calidad de vida como: "la percepción que un individuo tiene de su lugar en la existencia, en el contexto de la cultura y del sistema de valores en los que vive y en relación con sus objetivos, sus expectativas, sus normas, sus inquietudes. Se trata de un concepto muy amplio que está influido de modo complejo por la salud física del sujeto, su estado psicológico, su nivel de independencia, sus relaciones sociales, así como su relación con los elementos esenciales de su entorno"(1).

El concepto de salud siempre ha estado ligado íntimamente a la enfermedad a lo largo de la historia, actualmente existe la necesidad de explicar los fenómenos que surgen a partir de la ausencia de enfermedad y ver al ser humano como un ser biopsicosocial por lo cual se sugiere estudiar los diferentes factores relacionados con los aspectos biológicos, ambientales, sociales y económicos que se relacionan con el estado de salud de un individuo. Cuando hay una problemática de salud esta no debe ser enfrentada de manera individual sino en sociedad, debido a que es allí a donde pertenece el individuo. Es por ello por lo que la salud es considerada un concepto dinámico debido a que incluye factores tanto de carácter interno como externo, es decir, que no depende solo de características fisiológicas sino también de experiencias personales, familiares, características ambientales y sociales que involucran a la sociedad en general (2).

Por otra parte, la salud percibida es un indicador excelente para aproximarse a la situación de salud actual del individuo que se está tratando, el término autopercepción de la salud se refiere a la información brindada por el individuo sobre su estado de salud de acuerdo con sus conocimientos e interpretaciones desligado del concepto médico, es decir, es de carácter subjetivo que puede orientar sobre sus problemas de salud (3).

De esta manera, dentro de las etapas del desarrollo del ser humano se encuentra la adolescencia, en la cual se desarrolla la identidad sexual. Por ello la población adolescente es susceptible a cambios tanto físicos como fisiológicos y emocionales (4). Se debe considerar al adolescente de manera integral, teniendo en cuenta tres grandes áreas de desarrollo: etapa temprana, entre los 10 y los 13 años, en ella se da la preocupación por los cambios físicos que se viven, la etapa media, entre los 14 y los 16 años donde inicia la vivencia de la propia sexualidad, existe el máximo nivel de conflictos con los padres y surgen los deseos de experimentar para así, en la etapa tardía, entre los 17 y los 19 años, priorizar las relaciones íntimas, donde se logra la aceptación de la imagen corporal. Una de las tareas de la adolescencia es lograr una independencia emocional de los adultos y establecer relaciones sociales (5).

Según Erikson la adolescencia corresponde a la etapa 2 Autonomía vs Vergüenza y Duda en esta crisis necesitan lograr el equilibrio justo entre la autonomía y el control externo, necesitan aprender lo que pueden y deben hacer, lo que es seguro de hacer, y qué clase de guía necesitan aún de sus padres (6).

Según la OMS existen diversas situaciones que pueden llegar a afectar la salud en la población adolescente y por ende la calidad de vida y la forma como sus padres la perciben tales como: embarazos y partos precoces, los cuales pueden llevar incluso a perder la vida, enfermedades de transmisión sexual, que afectan a más de 2 millones de adolescentes, problemas de salud mental, entre ellas la depresión, la cual es la tercera causa principal de morbilidad y discapacidad entre los adolescentes y el suicidio que es la tercera causa de defunción entre adolescentes mayores de entre 15 y 19 años, la violencia, la pobreza, la humillación y el sentimiento de desvalorización pueden aumentar el riesgo de padecer problemas de salud mental (7-12). La violencia es una causa importante de mortalidad entre adolescentes de sexo masculino, el uso de alcohol y drogas aumentan los comportamientos de riesgo como tener relaciones sexuales sin protección, también la probabilidad de muerte y finalmente los problemas nutricionales como la malnutrición o la obesidad, que conllevan a contraer enfermedades e incluso la muerte $(13-17)$.

La medición de la calidad de vida y la percepción de la misma actualmente cuenta con diversos recursos que facilitan su medición, entre ellos encontramos KIDSCREEN-27 para padres, incluyendo la subescala aceptación social del KIDSCREEN-52 pues esta permite evaluar el efecto del bullying o acoso escolar en la calidad de vida, existen tres versiones: KIDSCREEN-52, KIDSCREEN-27 y KIDSCREEN-10 se usan tanto para padres como para niños. En Latinoamérica estos instrumentos han sido usados en Argentina, Chile y Colombia (8-10). 
La salud percibida puede ser referida por los propios sujetos en el caso de los adultos y personas mayores. También es frecuente que, en el caso de la población de niños y jóvenes, se tenga en cuenta la percepción a través de los acudientes o padres, los cuales se convierten en una fuente alterna de información, pues dan una perspectiva diferente que debe tenerse en cuenta para obtener una imagen más completa de la calidad de vida del niño o adolescente (10-12).

Estos instrumentos generalmente evalúan diferentes dimensiones de calidad de vida relacionada con salud en una escala Rash: el KIDSCREEN-52 mide 10 dimensiones bienestar físico, bienestar psicológico, estado de ánimo, autopercepción, autonomía, relación con los padres y vida familiar, amigos y apoyo social, entorno escolar, aceptación social (bullying), y recursos económicos. Se construyó y probó en una prueba piloto utilizando los datos de más de 3000 niños y adolescentes europeos. El KIDSCREEN-27 cuenta por su parte con cinco dimensiones: bienestar físico, bienestar psicológico, autonomía y padres, amigos y apoyo social, entorno escolar. Por último, la KIDSCREEN-10 es unidimensional (8-10).

Algunos padres en Chile expresan que, debido a la falta de comunicación que existe entre padres e hijos adolescentes, es poco lo que conocen acerca de su salud sexual y de las dudas que tienen sus hijos sobre la sexualidad. Además expresan que su principal preocupación radica en embarazos precoces y enfermedades de transmisión sexual (18). La percepción sobre el funcionamiento familiar puede variar ampliamente desde el punto de vista del padre al percibir a su hijo adolescente, pues es el adolescente quien se ve mayormente afectado. Esta situación implica una gran crisis para el adolescente pues sufre luto por la pérdida de su infancia, no comprende que esta etapa de la vida es un acontecimiento vital esperado, puede interpretar estos cambios en su vida como algo negativo y sentir incomprensión por parte de sus padres (17). Es allí donde radica la importancia de este artículo que busca describir la percepción que tienen los padres respecto al estado de salud y al bienestar de sus hijos escolarizados de 15 a 18 años.

\section{Metodología}

La metodología fue un estudio cualitativo, clasificado según la técnica de recolección de datos con el abordaje de grupo focal, el cual utiliza la entrevista grupal semiestructurada. Esta metodología procura que un grupo de individuos discutan y elaboren, desde la experiencia personal, una temática o hecho social que es objeto de investigación y se recomienda conformar grupos entre 5 a 10 participantes (19). El proceso de análisis de modo general consistió en organizar, construir un significado, codificar y relacionar y, por fin, escribir las respectivas categorías que fueron emergiendo de los datos.

Respecto a los participantes para este estudio se conformaron 2 grupos focales, el procedimiento que se llevó a cabo consistió en que, con previa autorización por parte de las directivas de la institución, se extendió la invitación en una actividad llamada 'Escuela para Padres' realizada por la institución. En ella participaron 22 padres de familia. Posteriormente se realizó una nueva invitación a los 22 padres de familia por medio de llamada telefónica, creando los dos grupos focales con 11 participantes para el grupo $1 \mathrm{y}$ 11 para el grupo 2 y se citó a cada grupo en diferentes fechas. El día de la cita, de cada grupo sólo asistieron al lugar 5 padres de familia, se les explicó de forma detallada el propósito del estudio de investigación, se establecieron conceptos éticos como la autonomía por medio de la participación voluntaria y la firma del consentimiento informado el cual se realizó previo a las entrevistas.

A los dos grupos focales de padres de familia de adolescentes escolarizados entre 15 y 18 años, de los grados $9^{\circ}, 10^{\circ}$ y $11^{\circ}$ grado de una institución educativa pública de la ciudad de Bucaramanga, se les formularon 10 preguntas semiestructuradas. El tiempo de las entrevistas fluctuó entre 60 y 90 minutos.

Se contó con el investigador principal como agente facilitador para los grupos focales que se encargó de dirigir la entrevista y dos investigadores como observadores que tomaron nota de la actividad desarrollada a través de un diario de campo. La información fue grabada con la aceptación de los participantes. La entrevista se transcribió y se realizó un análisis de contenido que permitió la organización de las diferentes categorías y subcategorías.

Una vez obtenida la información de los sujetos investigados, se obtuvieron las grabaciones, en ellas el grupo 1 duró 90 minutos y las del grupo 2 duró 60 minutos. Se procedió a transcribir la entrevista previamente grabada y se realizó el análisis de contenido mediante una lectura lineal en la que se fraccionaron los diferentes apartados para la creación de codificación de contenido y esto permitió identificar las respuestas de los sujetos entrevistados. Posteriormente se realizó una segunda lectura, para 
agrupar las diferentes respuestas codificadas con cada pregunta de la entrevista. A continuación se generaron categorías y subcategorías preliminares, con su respectiva codificación, las cuales fueron propuestas por los investigadores con base en la información de la literatura y sin dejar de lado la categoría de los aportes de los sujetos investigados. Además fue necesario realizar una lectura entre líneas para algunas respuestas codificadas con el fin de ubicarlas en las categorías. Finalmente, se reagruparon las diferentes categorías y subcategorías.

Dentro de los criterios que se tuvieron en cuenta para la validez del estudio, se contemplaron:

- Saturación de los datos: en donde la mayoría de las categorías y subcategorías se lograron obtener la mayor cantidad de datos y por ende mayor saturación de información.

- Credibilidad: está centrada en los diferentes discursos dados por los padres partiendo desde sus diferentes experiencias como padres y en relación con sus hijos adolescentes.

- Confirmabilidad: se realizaron grabaciones en audio de las entrevistas con cada grupo focal para posteriormente transcribirlas, codificarlas y agruparlas en las diferentes categorías y subcategorías, y finalmente confrontar con la literatura.

- Relevancia: para este criterio se hallaron nuevas categorías teniendo como referencia la literatura relacionada con los diferentes instrumentos que valoran la calidad de vida y esta, a su vez, relacionada con la salud. Tales categorías corresponden a los hábitos alimenticios, a las relaciones interpersonales, la tecnología, la sexualidad y la actividad física y la espiritualidad.

Criterios de inclusión: los criterios de inclusión que se tuvieron en cuenta para la conformación de los grupos focales fueron: padres de adolescentes de 15 a 18 años, padres de estudiantes de $\operatorname{los}$ grados $9^{\circ}$, $10^{\circ}$ y $11^{\circ}$ y padres de adolescentes escolarizados de una institución educativa pública de Bucaramanga, Santander.

Criterios de exclusión: los criterios de exclusión que se tuvieron en cuenta para la conformación de los grupos focales fueron: padres que no acepten de forma voluntaria la participación en el estudio, cuidadores que no sean los cuidadores principales y adolescentes con enfermedades crónicas.

\section{Resultados}

Los resultados se presentan en dos grandes apartados: el primero corresponde a las características sociodemográficas de los participantes (Tabla 1) y el segundo apartado son las categorías y subcategorías que emergen sobre el concepto de salud y sus componentes (Figura 1). Allí se incluyen aquellas situaciones positivas y negativas que afectan la salud.

Tabla 1. Características sociodemográficas de los padres y adolescentes

$\begin{array}{lll}\text { VARIABLE } & \text { II } & \%\end{array}$

Características de los padres

Sexo

\begin{tabular}{|lll} 
Masculino & 2 & $20 \%$ \\
\hline Femenino & 8 & $80 \%$ \\
\hline Edades de los padres & & \\
\hline $30-39$ años & 4 & $40 \%$ \\
\hline $40-49$ años & 4 & $40 \%$ \\
\hline $50-59$ años & 2 & $20 \%$
\end{tabular}

\section{Características de los adolescentes}

Sexo

$\begin{array}{lll}\text { Masculino } & 5 & 50 \% \\ \text { Femenino } & 5 & 50 \%\end{array}$

Edad de los adolescentes

15-18 años

$10 \quad 100 \%$

Nivel de escolaridad de los adolescentes

9-11 nivel de secundaria

$10 \quad 10 \%$

Auto-reporte estrato socioeconómico

$\begin{array}{lcc}\text { Bajo (1-2) } & 5 & 50 \% \\ \text { Medio (3-4) } & 5 & 50 \% \\ \text { TOTAL } & 10 & 100 \%\end{array}$

Fuente: elaboración propia.

Respecto a las características sociodemográficas de los participantes a los grupos focales se destaca que en su totalidad los participantes son procedentes de la ciudad de Bucaramanga, se contó con la presencia de un padre de familia de sexo masculino por cada grupo focal y cuatro de sexo femenino. Dentro de las características de los hijos se encontraron: escolarizados entre los 15 y 18 años, discriminados por sexo, 5 hombres y 5 mujeres distribuidos equitativamente en cada grupo 
focal. Los participantes tenían un nivel de formación de grados de secundaria $9^{\circ}, 10^{\circ}$ y $11^{\circ}$ y pertenecían a estrato socioeconómico bajo y medio distribuido equitativamente.
Posterior a la lectura de las entrevistas y agrupación de las narrativas se lograron obtener 11 categorías y 6 subcategorías (Figura 1).

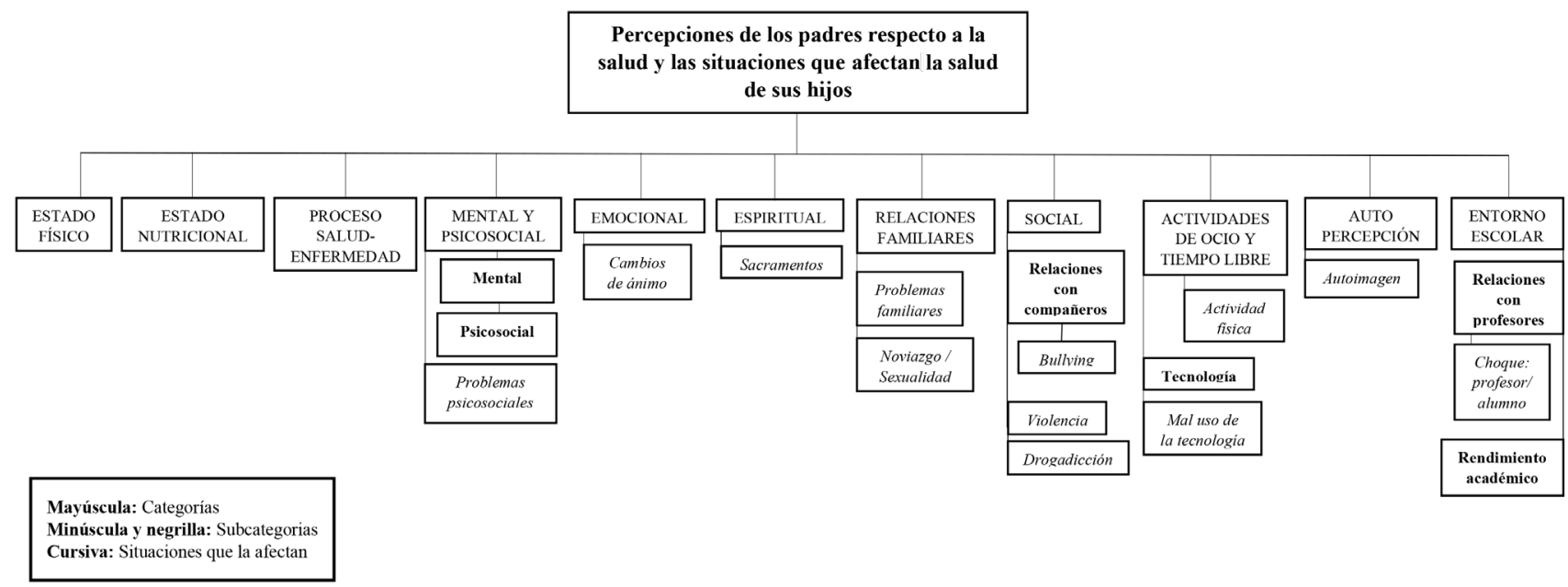

Figura 1. Categorías y subcategorías definitivas

Fuente: elaboración propia de los autores

\section{Categorías y subcategorías sobre las percepciones respecto a la salud y las situaciones que la afectan.}

Estado físico: en esta categoría se agruparon las narrativas de los padres en las que se identifica al estado físico como un componente de la salud. Se presentan algunos ejemplos que representan esta categoría. "Bueno uno siempre cree que cuando hablan de la salud es como el estado físico..." (E1MG1P1). "Pues en la salud lo que estábamos hablando ahora, mirarle cómo está físicamente" (E3FG1P8). “Para mí o sea que esté bien físicamente tanto cualquier enfermedad que tenga" (E3FG2P1).

Estado nutricional: es identificado como un aspecto a tener en cuenta en la salud de los adolescentes a continuación se presentan algunas narrativas de los padres respecto a este componente.

"Bueno uno siempre cree que cuando hablan de la salud es como... la alimentación, cómo se encuentra el sardino: si bien alimentado, mal alimentado..." (E1MG1P1). "Si vamos a la salud física, mi hijo sí... en cuestión de comida casi, casi que es vegetariano, o sea él come la carne pero o sea la verdura, uno hace la ensalada, la pone en la mesa y hay que meterle ${ }_{i}$ No se la coma toda!, en esa cuestión, porque prefiere más bien como en cuestión de comida" (E3FG1P5).

Proceso salud-enfermedad: los padres logran identificar el estado de salud afectado por la enfermedad. A continuación, se presentan algunas narrativas de los padres respecto a este componente. "Tanto cualquier enfermedad que tenga" (E3FG2P1). "...Yo supongo que a eso es a lo que le refiere a uno la salud, ...las enfermedades" (E1MG1P1). "Lo otro sobre sus enfermedades normales, eso es salud por ejemplo gripa, que le dio alergia, que está mal del oído, de los ojos y todas esas cosas" (E4FG1P1).

Mental y psicosocial: la parte mental y psicosocial está incluida dentro de la salud y es de vital importancia en el reconocimiento de los adolescentes. Dentro de esta categoría evidenciamos 2 subcategorías (mental, psicosocial).

Mental: hace referencia a aquellas situaciones que los padres logran identificar y que afectan el equilibrio entre lo físico y lo mental. Lo anterior se evidencia en las narrativas de algunos padres. "El cuerpo y la mente en equilibrio" (E2FG1P2). "Cómo está mentalmente, y el bienestar sería algo de cómo está, cómo se siente, ante todo, ante la familia, el colegio, ¿está bien o está mal?, pero está bien a lo que él piensa o a lo que nosotros pensamos..." (E3FG1P8). 
Psicosocial: esta subcategoría hace referencia a los diferentes problemas de tipo psicosocial que pueden presentar los adolescentes y que en ocasiones los padres no logran identificar. Esto se evidencia en los grupos focales. "...Eh... Psicosociales o sea que hay muchos jóvenes que tienen problemas psicológicos y a veces los papás no sabemos y pensamos que están físicamente bien, pero tienen problemas psicológicos y nosotros como padres no nos damos cuenta porque no tenemos pues esa preparación a veces los padres no tienen los conocimientos necesarios para saber qué problema psicológico pueden tener nuestros hijos" (E2FG1P2).

Situaciones que afectan el componente psicosocial: los padres logran identificar estas situaciones de tipo psicosocial que pueden llegar a afectar a sus hijos. "Si, o sea este qué problemas psicosociales que puede presentar mi hijo" (E2FG1P3). "Sabes es entender pues psicológico en la manera de actuar y en la manera de ser mirando como la manera que él piensa de la vida y qué piensa de las cosas" (E5FG1P2). “...Eh... Pues como todo en general tanto psicológicamente..." (E4FG1P1).

"Se ve en lo psicológico" (E1FG2P1).

Emocional: esta categoría hace referencia a aquellas situaciones que se evidencian en los adolescentes si se tiene una adecuada relación padre e hijo. En los diferentes discursos de los padres transcritas a continuación se presentan algunas narrativas al respecto. "Pues la parte emocional, cuando los hijos tienen como problemas se manifiestan de alguna manera, ¿sí? Y pues uno los conoce ya como son y empieza a ver como que el estado de ánimo baja, a veces no comentan las cosas, se deprimen" (E3FG2P8). "La parte emocional también es muy importante porque eso cubre bastante el estado" (E2FG2P1).

Situaciones que afectan el componente emocional: en donde las alteraciones del estado de ánimo afectan directamente la salud. "Ella es muy sonriente y, cuando está mal, llega, se ríe y pasa de una vez para la pieza, ni saluda, como le pregunta qué le pasó y ella dice: "nada"; y uno ya sabe que algo pasó" (E4FG2P8). "Su rostro lo refleja todo, de si es por enfermedad, si es por bajo de ánimo, si es porque están alegres porque van hacer algo..." (E4FG1P10). "Conocerlos, porque... conocer cómo son, porque por lo menos mi bebé es así toda alocada y esa cuestión y ella siempre llega alegre y hace poco llegó cabizbaja, algo pasó, entonces si tú lo conoces y sabes cómo es, entonces ahí se va a dar cuenta rápido si algo está pasando porque ellos cambian su personalidad, su forma de ser, entonces uno está alerta de una vez, o sea yo pienso que si nosotros los conocemos bien y tenemos una buena relación con nuestros hijos, nos vamos a dar cuenta pronto lo que está pasando..." (E2FG1P8).

Espiritual: esta categoría hace referencia a aquellas creencias de tipo espiritual que aportan a la salud de los adolescentes. Se evidencian en los relatos de algunos padres a continuación. "Pues para mí el bienestar tanto físico como psicológico de los niños en la parte espiritual, o sea, todo lo que encierra el bienestar de ellos" (E3FG2P1). "Pues para mí es muy importante, o sea porque uno desde pequeñitos les enseña a ellos y a veces cuando entran a la adolescencia, como que dejan de lado todo eso, lo digo porque la que tiene 15 años, cuando tenía siete u ocho años siempre le escribía cartas a Dios, yo decía: "esta chinita va a ser como monja", luego llegó a la adolescencia y dejó todo eso, a veces me doy cuenta que por estar tan alejada, a uno las cosas no le salen como uno quiere" (E1FG2P6).

Situación positiva del componente espiritual: el cumplir con los sacramentos, que es la iniciación cristiana en la vida de los católicos, es identificado como un aporte positivo a la salud de sus hijos. "Yo el año pasado lo metí a la confirmación y ahora todos los sábados lo metí allá y estoy buscando meterlo en el grupo juvenil hay muchachas buenas que son decentes que le temen a Dios, respetan a ellas mismas y se valoran, los chicos que están en eso ellos son muy respetuosos yo le digo usted no se puede soltar de la mano de Dios" (E2FG2P9). “...En todo momento uno habla mucho con él y él dice "mami, yo nunca" porque él ve los muchachos por ahí cómo se dañan la vida y dice: "no, yo nunca haría eso" y Dios quiera que mis hijos no vayan a hacer eso, pero de todas maneras él sea como sea es muy creyente en Dios y eso es algo que yo les he inculcado a todos mis hijos..." (E5FG1 P7).

Social: esta categoría habla acerca de la manera en la que los adolescentes socializan con sus pares y lo que esto puede aportar a su salud, ya sea de manera positiva o negativa, según los relatos de algunos padres. “...cómo ellos también se socializan, cómo se integran con las demás personas también en eso; como la parte social de ellos" (E1FG2P1).

Relaciones con compañeros: en esta subcategoría los padres hacen evidente la importancia de las relaciones entre adolescentes, las diferentes situaciones a las que se pueden enfrentar y los diferentes roles que asumen. “...También uno debe de estar muy pendiente del 
círculo de amigos que ellos tienen, sus amiguitos..." (E4FG1P9). "Ellos buscan es hacer amigos y no saben a veces con quién" (E2FG2P9).

Situaciones negativas que afectan el componente social: entre estas situaciones los padres logran identificar la violencia, drogadicción y sexualidad como factores que afectan la salud de sus hijos de manera significativa.

- Violencia: un padre refiere en su discurso acerca de la violencia, que esta se evidencia debido a la movilidad de población que actualmente se presenta en el país (desplazamiento interno entre regiones) y que puede llegar a afectar a sus hijos. “.....Sí, allá hay violencia impresionante y no por la gente nativa, sino porque ha llegado mucha gente de otros lugares a querer adueñarse del pueblo y entonces está el que mata, está el capo, como dicen ellos, pero la gente como tal tenía esa cultura de que «Yo soy la vecina y yo regaño al niño de una manera bonita porque la mamá en este momento no está, entonces yo le digo al niño "no haga eso porque tal cosa" y cuando llega la mamá del niño le dice y la vecina le dice "ah sí, muy bien, gracias"», pero acá alguien le dice algo a un niño y la mamá y el papá se alborotan de una manera que entonces para qué me meto. Yo nunca le he dicho nada a nadie, y lo que he visto... o sea, la gente se alborota y hablan tan golpeado, tan feo, tan... ¿qué está haciendo?, si la mamá no le dice nada, porque después el culpable es el que trató, o se van y le dicen a la mamá «jay! Vea que yo vi...» «no, mi hijo no es así» Mejor dicho... Se ofenden, entonces... y termina pagando los platos rotos el que trató de avisar" (E3FG1P3).

- Drogadicción: los padres logran identificar que la problemática social de la drogadicción puede afectar a sus hijos. "Pues las drogas los pueden afectar mucho..." (E4FG1P3). "Es muy fácil que los muchachos caigan en eso, pero también es muy fácil de que vean gente... como les digo yo a ellos, hay gente que dice "yo lo controlo"... Entonces yo les digo a mis hijos "vea, ese que está durmiendo allá en el andén, oliendo feo, sin comer, él lo controlaba” (E3FG1P3). “...ese ha sido uno de los problemas más grandes de pronto de ver tanto joven por ahí en la calle con vicio, o sea, que vean tan normal eso de coger de pronto un cigarrillo y pararse en una esquina y fumarlo y que lo vean tan normal porque eso es lo que se ve hoy en día, pero en las consecuencias de eso puede ser que haya sido del hogar" (E5MG2P3).

Relaciones familiares: en esta categoría los padres hacen referencia a aquellas situaciones que se viven dentro del entorno familiar que pueden afectar de alguna manera la salud de sus hijos. "La familia es muy importante porque los ayuda a formarse y a salir de los malos ambientes, o sea que hay varios ambientes que los pueden acorralar, ese es el ambiente en la casita..." (E1FG2P3).

"A veces ellos generalizan por otro punto de vista y allí es donde se desvían porque uno no tiene la manera de cómo ayudarlos a ellos y allí entonces es donde se van por las drogas, porque los papás no estamos pendientes en ese momento que ellos nos necesitan y ellos lo canalizan de otra manera" (E2FG1P3).

\section{Situaciones que afectan dentro del entorno familiar:} en el entorno familiar los padres identifican situaciones, como problemas familiares, que pueden afectar de manera directa e indirecta a los adolescentes. "Cuando hay problemas así de familia de casa, por lo menos una separación, un divorcio, un problema con algún otro hermano" (E3FG2P3). "Pues yo pienso que también el abandono familiar, porque nosotros creemos, o los padres creen, que ya él está grande y ya él se defiende solo, no el abandono donde lo dejó solo del todo, pero muchos cuando ya entran al bachillerato, se dice: "no, ya está en bachillerato y ya puede hacer las tareas solos", ya si mucho se le pregunta: "- ¿tiene tareas?, - no" y muchos: "jum, no, mi hijo me dijo: "no tengo tareas"", entonces eso es un abandono; o cuando están en primaria si tiene tarea venga le leo eso, mejor dicho, van por él, le cogen el cuaderno, le miran, le hacen, y ya cuando van creciendo ya es si muchos algunos no, se limitan solo a "tiene tarea" y hay otros que ni siquiera preguntan entonces para mí eso es irlo abandonando..." (E3FG1P3).

Noviazgos: los padres identifican que el noviazgo afecta negativamente debido a la edad en la que se encuentran los adolescentes. "Es que les afecta bastante, yo también le digo eso a mi hijo, que porque es que ustedes no son unos bebés y empiezan a aburrirse, y la vecina de al lado es la novia, y lo tiene torturado esa muchacha, y no, no, no le sirve y no, y yo me metí en eso, y prácticamente hice que eso se acabara y emocionalmente está malo; de todos modos, él da la vuelta y arrastra los pies como para que la vieja lo vea, y yo: "de por Dios, míreme a mí, mire cómo estoy yo, por favor, concéntrese en estudiar, que las mujeres dan puros gastos y de todo"" (E2FG2P3). 
“...el otro problema de los adolescentes ahorita es que cuatro o cinco niñas y ya entre las cuatro o cinco niñas buscan a ver cuál es la más bonita, y de las bonita entonces ya la van a coger contra ella porque el niño que a la otra le gusta entonces a ella también, entonces ahí es donde empiezan las rivalidades, y si de pronto una niña que no haya tenido de pronto la confianza que le contó se queda callada, y en el momento que ella se queda callada o puede que la agredan a ella, o ella puede defenderse de la manera también igual, entonces ya va a decir uno uno: "¿por qué no me contó?, ¿por qué no me dijo a mí?, nosotros fuéramos hecho algo""' (E5MG2P9).

Sexualidad: los padres logran identificar la sexualidad como una situación que puede llegar a afectar la salud de manera negativa debido a la edad en la que se encuentran sus hijos y a su inexperiencia. "Nosotros a los muchachos siempre les hablamos, así como se dice, a calzón quitado, porque eso era en el tiempo de antes que uno estudiaba y nunca le decían nada, ni siquiera cómo era cuando le iba a llegar el periodo por primera vez, ni nada. Ahora eso desde preescolar ya les están explicando que uno como padre debe de decirle, por ejemplo, "eso puede ser así, no se deje llevar de esta forma", porque son cosas que le pueden afectar en la salud tanto que él puede estar con otra pelada y la puede dejar embarazada y ya vienen los problemas y eso y hay que evitar las cosas y enseñarles también que ellos quieren probar de todo rápido entonces hay que decirles ya tienen 15 y 16 años todo eso es con calma, mire que eso le puede ponerle como ejemplos, que ellos sepan pero tampoco cohibirlos de todas las cosas" (E4FG1P7). "Pero lo que pasa es que el sexo no es malo, sino que si uno no habla con ellos de eso ellos se van por ese lado y se les va quedando esa" (E3FG1P3). "No, pero eso es una adicción, no el sexo, sino como la pornografía" (E4FG1P3). "Y que a nosotros como papás nos da pena a veces hablar con los hijos sobre el sexo" (E1MG1P3).

Actividades de ocio y tiempo libre: en esta categoría los padres hacen referencia a aquellas actividades que en algunas ocasiones afectan la salud de sus hijos de manera positiva $y$, en algunas otras, de manera negativa, ya que algunos de ellos tienden a descuidar sus otras actividades escolares por estas actividades. Lo anterior se evidencia en los relatos de algunos padres presentados a continuación. "De pronto la falta de hacer cosas aparte de estudio, hobbies. Mi hijo está en atletismo, en el colegio, y el mayor está en danzas, en PRE-ICFES y mantienen muy ocupados; entre más tiempo de ocio tenga, menos tiempo de hacer cosas malas. Como ayer, me dice que no sabe que le den a fumarse un cigarrillo a tomarse un alcohol que no le ve la gracia a la Cola \& Pola, y al refajo. Gracias a Dios él desde siempre ha estado muy ocupado, el único día libre es el domingo, y ese es día de familia" (E2FG2P9). "...Y pues el deporte lo mantiene concentrado y no lo deja tanto, porque se requiere mucha concentración" (E4FG1P5). "En mi caso, tengo dos hijas, también están en danzas, y cuando no están en danzas, están en el colegio o en la casa conmigo; eso les ayuda muchísimo en la parte motriz, social y disciplina, es una academia que les exige mucho" (E4FG2P5).

Tecnología: en esta subcategoría los padres hacen referencia a los diferentes beneficios que trae el uso de la tecnología en la actualidad, pero también a aquellas cosas o situaciones no deseadas que genera el uso de la tecnología de manera inadecuada. Estos puntos se evidencian en los siguientes parafraseos. "De pronto mis hijos, leen mucho, ellos leen... o sea cuando... uno hay veces por la mañana, usted la ve pegada al celular y piensa que está chateando pero no, apenas lo tiene así, va a ver y está leyendo, o sea ella descarga libros. Y así también es el niño, "no, es que yo estaba leyendo" o "mamá, mira que yo leí esto así...". En esa cuestión, ellos se van más por lo intelectual" (E3FG1P5). Por lo anterior, los padres refieren lo siguiente en sus discursos: "Cómo controlarle un poco la tecnología, porque es que...” (E1MG1P7).

Situaciones que lo afectan: se reconoce el mal uso de la tecnología como una afección a la salud.

"...igual la tecnología porque se vuelve una adicción y si no están a toda hora ahí, es una adicción que no pueden comer, no pueden ver ni televisión, ni compartir con la familia sino todo el tiempo con los dispositivos" (E4FG1P3). "Hay gente o hay sardinos que están cambiando la forma de alimentarse o los horarios de alimentarse por estar pegados en la tecnología, ahora todos los sardinos se sientan, sentémonos a almorzar y una cucharada de sopa y péguele a la tecnología y creo que el cambio de alimentación o el cambio de horarios de alimentación de estar cambiando alimentos saludables por alimentos malos por estar pegados en la tecnología les está influyendo mucho en la salud" (E1MG1P3). "Afecta muchísimo que todo mundo tenga celular, eso se vuelve como una adicción, eso afecta tanto en casa como la concentración en el aula de clase..." (E2FG2P3). "Cuando mi hija no tenía internet leía, ahora que tiene celular no ha vuelto a coger un libro, ella me dice que qué va a leer, si no tiene nada, que la deje" (E1FG2P3). "Y todo lo que ellos miran les puede contaminar su mente, ¿no? 
porque no todo es bueno lo que ellos están mirando ahí y ya ellos, por ejemplo los jóvenes, ellos van a querer ver muchas veces sexo, ellos, como se dice, están probando entonces todo quieren saber y si algún muchacho les comentó "algo hay en tal canal, hay tal cosa; ay, yo quiero mirar", porque no se va a conformar sólo con que el compañero le mostró o le dijo" (E4FG1P3).

Autopercepción: la categoría de autopercepción hace referencia a los diferentes cambios que sufren los adolescentes, que son evidenciados tanto por ellos como por sus padres y que en ocasiones afectan el estado de salud, ya sea de manera positiva o negativa. Esto lo refieren algunos padres en sus discursos. "Que hay mucho cambio de personalidad en ellos, ya van cambiando su personalidad y ya quieren hacer lo que ellos dicen y ya hay momentos en los que ya uno no los puede controlar para no llevarles la contraria; entonces, si volvemos otra vez a la tecnología, pues ahí viven ellos, y se la pasan ahora que en YouTube y diciendo: "yo quiero ser así", o "yo quiero esto porque mi compañero también lo tiene o también es así", entonces ya ellos empiezan a cambiar su personalidad, su forma de ser y a crear su propia personalidad; y ahí es donde tenemos que estar, pues, muy pendientes a ver qué es lo que ellos quieren ser en esos momentos" (E2FG1P6). “...Entonces ellos están buscando qué quieren ser" (E2FG1P6). "También el sentido de ellos de cómo se visten, cómo ellos se manifiestan ante las personas, porque se ve mucho en los niños que cambia en lo físico, ya vienen jóvenes que se pintan el cabello, se ponen piercing, tatuajes, entonces ellos a través de eso expresan muchas cosas, como ansiedad, también por ese medio le da a entender a uno" (E4FG2P1).

Situación negativa que afecta la autopercepción, autoimagen: dentro de la categoría de autopercepción, por medio de los relatos de los padres, logramos identificar situaciones que afectan de manera negativa la salud y que se evidencian en el siguiente parafraseo. "Pero por lo menos la mía, una, la menor, es la impulsiva, es la que le gusta probar, es la que le gusta colocarse el piercing, la que le gusta tatuarse, ella es así, entonces ella me da miedo por eso, porque le gusta probar, ir probando las cosas..." (E2FG1P3).

Situación positiva relacionado con la autopercepción, autoimagen: algunos padres también identifican la autopercepción de manera positiva, ya que estos cambios, cuando los permiten, les ayudan a la búsqueda de su personalidad. "Todo es cómo se haga porque, por ejemplo, esos cambios también los hacen los adultos y todo es el cómo lo haga la persona porque pues digamos pintarnos el pelo todo el mundo se quiere pintar el pelo y hasta a hombres que ya les salen canas uno los ve y dice: "pero tan negro el pelo de ese señor y no es natural", pero es mirar bueno, ¿por qué es que se quieren pintar el cabello? Porque se quieren...y es conversar, o sea, yo digo que el diálogo va mucho, dialogar con ellos, no decir: "yo soy el papá y acá se hace lo que yo digo"” (E3FG1P8).

Entorno escolar: dentro del entorno escolar los padres evidencian un ambiente en donde los adolescentes pueden encontrar diferentes situaciones de riesgo ejemplificadas en los relatos. Dentro de esta categoría se lograron identificar tres subcategorías: relaciones con pares, profesores y rendimiento académico.

Situaciones negativas que afectan el entorno escolar: los padres reconocen el bullying y las relaciones de noviazgos como posibles afecciones a la salud.

- Bullying: algunos padres identifican el acoso escolar como una afección a la salud directa. “...Y no solo eso familiar, sino en el colegio también, cuando hay eso de bullying, el matoneo" (E3FG2P3). "El bullying, porque hay compañeros que lo amenazan, por ejemplo, mi hija es nueva acá, y ahí está por los compañeros que hacen amistades para conocerse, cierto, entonces hay una niña que empezó amenazarla, ya empezó a echarle los otros amiguitos de enemigos, se enamoró de un compañerito y el compañerito le prestó el saco a ella y así, ella se sentía mal pues me contó en la casa y yo le dije "esperemos a ver qué pasa, si la niña se sigue metiendo con usted, pues vamos arreglar en el colegio". Ya como que se la pasó y después la niña volvió hablarle, pues de que no la agreda y si la vuelve amenazar me dice. Pues, hasta hora está normal, pero la niña es demasiado agresiva y le gusta mucho amenazar a los compañeros" (E2FG2P3).

- Relaciones con profesores: dentro de esta subcategoría se evidencian aquellas situaciones que suelen presentarse con los profesores que pueden afectar la salud del adolescente, ya sea de manera positiva o negativa. Así son relatadas por algunos padres. "Entonces es una situación derivada dentro del entorno escolar de compañeros y otras que pueden venir derivadas de decisiones o cosas que se tomen también...las relaciones con los profesores y ven que eso les afecta o les favorece a ellos" (E3FG2P9). 
- Situación que afecta las relaciones con los profesores: los padres reconocen que en ocasiones los choques entre profesor y alumno pueden afectar a sus hijos. "Mi hijo tuvo un choque con un profesor, porque llega y me pregunta: "mamá, ¿ya tengo cara de vicioso?" y yo le pregunto: “¿por qué hijo?” y él y me dice que una profesora le dijo que él con esa cara de vicioso que tenía; yo de una vez le dije: "dígame quién es" y él me dijo: "no mamá, tranquila, problemas", yo le dije: "no hijo, eso no se puede permitir", "No mami, tranquila, yo le respondí a la profesora que me dijera dónde me veía las pullas, por el hecho de que yo sea delgado no significa que yo sea un vicioso, yo como y todo". ¿Qué tal?, ahora que porque es flaco, es que hay muchachos que comen y comen y comen y no se engordan" (E2FG2P8). "De pronto la forma de enseñar. Por lo menos, el año pasado, en la clase de religión a PEPITO le estaban enseñando... o sea, él llegó a la casa diciendo que Dios no existe, que nosotros venimos del polvo de estrellas, que porque... bueno, él empezó a... y yo ¿cómo así?, y le digo yo "mire que ni siquiera los de Discovery que indagan tanto... ellos empiezan a decir que no, que no y a lo último dan la conclusión de que no lo pueden probar", entonces empezamos a mirar y todo, pero... entonces acá estaban con eso de que nosotros veníamos del polvo de estrellas, del Big Bang, que no sé qué, y yo "si, eso son teorías pero nadie le puede decir a usted: sí o no", entonces los empiezan a confundir más de lo que la edad ya los tiene confundidos, o de pronto de lo que uno los tiene confundidos. Cómo así, si es lo único que centra al mundo, el hecho de pensar de que hay un Dios, de que existe un Dios, hasta uno, si uno no está bien cimentado en las cosas... pero entonces si el estudiante le lleva la contraria, está mal, porque el estudiante no está aprendiendo porque no está aprendiendo lo que el profesor le está diciendo, si no que le está llevando la contraria al profesor, entonces queda..." (E3FG1P3).

- Rendimiento académico: esta subcategoría hace referencia a la importancia del rendimiento académico y cómo este puede ser un indicador de salud en los adolescentes. Es descrito por algunos padres a continuación. "Creo que en los resultados del colegio, en los resultados de las notas, en los resultados de tareas, uno tiene que estar pendiente..." (E1MG1P8). "Sí, para mí es un indicador de salud, porque si mi hijo en el primer semestre o cada vez que entreguen notas, en el primer periodo le va bien y en el segundo me sale con que le está yendo mal, algo pasa, algo tiene que estar pasando, porque si estamos pendientes de los sardinos, su hijo, en el primer periodo le fue bien, en el segundo le fue bien, en el tercero le fue mal, o sea usted considera que el estudio no le da una base a usted pa' pensar que algo está pasando, yo considero que sí" (E1MG1P8). "Pero si usted lleva un balance de las notas, yo cojo los boletines de los sardinos, usted me dice: "tráigame los boletines del sardino que tiene 25 años ahorita", yo le traigo la carpeta. Pa' mí, eso es un bienestar, que en la nota refleje que están bien, bien en el sentido de que usted puede bajar 5 milésimas, pero un sardino que llegue a 5 y en el segundo periodo le salga a usted con un 1, o está pasando algo en el colegio o estoy haciendo algo mal, ahí se refleja el bienestar del sardino, creo, pa' mí” (E1MG1P8).

\section{Discusión}

En general, los dos grupos focales han permitido identificar 11 categorías y 6 subcategorías, además, las situaciones que las afectan. La discusión se presenta contrastando los resultados de este estudio con los hallazgos de otros investigadores, según las categorías y subcategorías que emergen sobre el concepto de salud y sus componentes, como se presentó en la Figura 1, en donde se incluyen aquellas situaciones positivas y negativas que afectan la salud.

\section{Estado nutricional}

Respecto al estado nutricional, se considera que el excesivo consumo de alimentos de alta densidad energética, ricos en grasas saturadas, azúcar y sal, la falta de actividad física y el incremento de actividades sedentarias, representan en la actualidad los estilos de vida de gran parte de la población, tanto infantil como adolescente (20). Este desequilibrio entre la ingesta y el gasto energético, sostenido por períodos de tiempo prolongados, ha sido reconocido internacionalmente como la principal causa de la elevada y creciente prevalencia de obesidad en esta población y que puede trascender a edades adultas.

Otro de los factores implicados en la obesidad infantil son la percepción parental inadecuada del estado nutricional de los hijos (20). En este sentido, los padres de este estudio manifiestan: "Bueno, uno siempre cree que cuando hablan de la salud 
es como... la alimentación, cómo se encuentra el sardino: si bien alimentado, mal alimentado...". (E1MG1P1), “...también cuando comen mis hijos son hombres y ellos... "Tengo hambre", y eso le pregunto... "Hijo, ya, ¿qué pasó?", y me dice: "no mamá, que me estoy engordando, mira cómo estoy" y empiezan hacer deporte también es la forma de alimentarse..." (E3FG2P8). En este punto se encuentra correspondencia entre la percepción que tienen los padres sobre la relación entre el estado de salud y la parte nutricional en los adolescentes.

\section{Proceso salud-enfermedad}

La adolescencia es una etapa de la vida en la que se suceden innumerables cambios, tanto físicos, como emocionales y sociales. Es en esta etapa donde también se toman decisiones y se pueden adquirir conductas de riesgo para la salud, entonces aparece la enfermedad. Por ello, es de vital importancia adquirir conductas saludables y de prevención de la enfermedad durante esta etapa $(6,7)$. Una de las narrativas en la que los padres señalan que este componente de la enfermedad permite identificar cómo está la salud de sus hijos es la siguiente: "...Yo supongo que a eso es a lo que le refiere a uno la salud, las enfermedades." (E1MG1P1)

\section{Bienestar mental y psicosocial}

El bienestar psicológico, el estado de ánimo y las emociones son determinados por la calidad de las relaciones entre padres e hijos. Esta última se asocia significativamente con la salud psicológica y el desarrollo de la adolescencia, es por ello que los padres con autoridad, o democráticos, tienen controles firmes sobre las conductas de sus hijos y hacen fuertes demandas encaminadas a la madurez. A la vez, son flexibles y están dispuestos a escuchar el punto de vista de sus hijos y frecuentemente se ajustan a los comportamientos de estos. Se considera este estilo de crianza como el ideal en la formación de los hijos porque se asocia con una alta autoestima y bajos niveles de depresión y ansiedad $(21,22)$. En este estudio los padres identifican la importancia de valorar el componente metal y psicoemocional de sus hijos como se presenta en alguna de las narrativas: "Cómo está mentalmente, y el bienestar sería algo de cómo está, cómo se siente, ante todo, ante la familia, el colegio, ¿está bien o está mal? ...” (E3FG1P8).

\section{Entorno escolar}

Las relaciones positivas, tanto entre los miembros de la familia como en la escuela, contribuyen en el apego de los adolescentes al ambiente escolar y, si hay una adecuada relación o integración entre familia y escuela, esto fortalecerá más aun los lazos del adolescente con el entorno escolar, pues pertenecer a dicho entorno irá más allá de la educación y de la adquisición de conocimientos. Este punto también incluye las relaciones sociales (23). Por lo anterior, los padres comentan: “...También uno debe de estar muy pendiente del círculo de amigos que ellos tienen, sus amiguitos..." (E4FG1P9)

\section{Estado emocional}

La adolescencia es una etapa voluble en la que se está expuesto a múltiples cambios tanto físicos como emocionales, por ello se debe propiciar un desarrollo cognitivo y emocional, buscar que los alumnos se puedan enfrentar a un mundo más complejo y competitivo con mayor oportunidad de obtener un bienestar general.

Como refiere el investigador Bisquerra, en su libro sobre Psicopedagogía de las emociones, sugiere que la educación emocional constituye un proceso educativo continuo y permanente, cuyo propósito es potenciar el desarrollo de las competencias emocionales como elementos esenciales del desarrollo humano. Esto, a fin de capacitar al sujeto para la vida, incrementando su bienestar personal y social. Los padres son quienes pasan la mayor cantidad de tiempo con sus hijos y conocen la expresión de sus diferentes emociones y sentimientos. Esto se hace evidente en narrativas como: "Conocerlos, porque... conocer cómo son, porque por lo menos mi bebé es así toda alocada y esa cuestión y ella siempre llega alegre y hace poco llegó cabizbaja, algo pasó, entonces si tú lo conoces y sabes cómo es, entonces ahí se va a dar cuenta rápido si algo está pasando." (E2FG1P8)

\section{Espiritual}

La espiritualidad puede considerarse un sexto factor de la personalidad que se define como: una motivación innata que orienta el comportamiento en el esfuerzo de construir un sentido más profundo para la vida desde una perspectiva escatológica (24). Las creencias religiosas pueden ser transmitidas de una generación a otra y ayudar en la promoción de conductas saludables mediante la proscripción de aquellas que no lo son o están en riesgo $(24,25)$. En la presente 
investigación, los padres identifican la espiritualidad como un elemento a fortalecer en los jóvenes y que, como padres, deben cultivar como parte de la salud. Esto puede apreciarse en algunas narrativas: "Yo el año pasado lo metí a la confirmación y ahora todos los sábados lo metí allá y estoy buscando meterlo en el grupo juvenil, hay muchachas buenas que son decentes, que le temen a Dios, respetan a ellas mismas y se valoran, los chicos que están en eso ellos son muy respetuosos yo le digo: "usted no se puede soltar de la mano de Dios"." (E2FG2P9)

\section{Social}

El o la adolescente, como individuo, también se relaciona con el medio que lo rodea, no puede ser ajeno a su influencia y muchas de sus acciones son el resultado de su interrelación, sea cual fuere la naturaleza de ésta. Pero ¿qué sucede con este ser en relación?, ¿cómo influye el entorno social en él o ella?, ¿el o la adolescente es capaz de sobreponerse a las condiciones adversas del medio?, ¿cómo lo hace? Estos son algunos interrogantes que se presentan cada vez que se intenta analizar los factores que influyen en el desarrollo de las capacidades del o la adolescente $(26,27)$. En este sentido, los padres identifican que el entorno puede afectar a sus hijos, ya sea de manera positiva o negativa, como se identifica en la siguiente narrativa: “...Sí, allá hay violencia impresionante y no por la gente nativa, sino porque ha llegado mucha gente de otros lugares a querer adueñarse del pueblo y entonces está el que mata, está el capo, como dicen ellos, pero la gente como tal tenía esa cultura de que «Yo soy la vecina y yo regaño al niño de una manera bonita porque la mamá en este momento no está, entonces yo le digo al niño "no haga eso porque tal cosa" y cuando llega la mamá del niño le dice y la vecina le dice "ah sí, muy bien, gracias"», pero acá alguien le dice algo a un niño y la mamá y el papá se alborotan de una manera que entonces para qué me meto. Yo nunca le he dicho nada a nadie, y lo que he visto... o sea, la gente se alborota y hablan tan golpeado, tan feo." (E3FG1P3)

\section{Autopercepción}

Durante la adolescencia, etapa de cambios físicos y psíquicos, la imagen corporal adquiere especial importancia, su insatisfacción puede contribuir a realizar prácticas inadecuadas (26). Los padres identifican este tipo de cambios que son muy evidentes en la adolescencia, como se evidencia en este estudio gracias a la siguiente narrativa: "También el sentido de ellos de cómo se visten, como ellos se manifiestan ante las personas porque se ve mucho en los niños que cambia en lo físico, ya vienen jóvenes que se pintan el cabello, se ponen piercing, tatuajes entonces ellos a través de eso expresan muchas cosas, como ansiedad, también por ese medio le da a entender a uno." (E4FG2P1)

\section{Relaciones familiares}

La transición que implica esta etapa del ciclo vital afecta a todo el grupo familiar y cobra real importancia que logren equilibrarse las demandas y los recursos disponibles. Por ello, se concluye que la adolescencia es una etapa en donde se necesita la asistencia de los padres o de miembros de autoridad para evitar que los jóvenes caigan en las diferentes conductas de riesgo que existen en el entorno ya sea social o en su defecto familiar (27-34).

Así, en este estudio, los padres manifiestan situaciones familiares que hacen pensar que las relaciones familiares afectan la salud de los jóvenes. Esto se aprecia en narrativas como: "Pues yo pienso que también el abandono familiar porque nosotros creemos o los padres creen que ya él está grande y ya él se defiende solo, no el abandono donde lo dejó solo del todo pero muchos cuando ya entran al bachillerato, ....cuando están en primaria si tiene tarea venga le leo eso mejor dicho van por él, le cogen el cuaderno, le miran le hacen, y ya cuando van creciendo... se limitan solo a «tiene tarea» y hay otros que ni siquiera preguntan entonces para mí eso es irlo abandonando..." (E3FG1P3)

\section{Actividades de ocio y tiempo libre}

El tiempo libre no es obligatorio y es considerado como: un conjunto de hábitos, actitudes, conductas, tradiciones, actividades y decisiones de una persona, frente a las circunstancias en las que se desarrolla en sociedad. El tiempo de ocio es un espacio destinado para que la persona haga lo que le guste, para su crecimiento y su desarrollo personal. Es el sujeto quien decide si es en beneficio propio, realizando actividades que no afecten su salud (35), o no. En el actual estudio los padres consideran que es importante guiar a los hijos en situaciones como el uso de la tecnología en el tiempo libre. Lo manifiestan así: "Igual la tecnología porque se vuelve una adicción y si no están a toda hora ahí es una adicción que no pueden comer, no 
pueden ver ni televisión, ni compartir con la familia sino todo el tiempo con los dispositivos" (E4FG1P3). "De pronto mis hijos, leen mucho, ellos leen... o sea, cuando... uno hay veces por la mañana, usted la ve pegada al celular y piensa que está chateando, pero no, ...está leyendo... "mamá, mirá que yo leí esto así. En esa cuestión ellos se van más por lo intelectual."

\section{(E3FG1P5)}

\section{Bienestar físico}

El estado físico es la habilidad de realizar un trabajo diario con vigor y efectividad, retardando la aparición del cansancio, realizado con el mínimo coste energético y evitando lesiones (36). En general, en este estudio se evidencia, desde la perspectiva de los padres, que la salud de sus hijos se ve afectada por diferentes situaciones que son coherentes con otros estudios reportados por la literatura. Este es el caso de los aspectos sociales, el o la adolescente como individuo también se relaciona con el medio que lo rodea, no puede quedar ajeno a su influencia y muchas de sus acciones son el resultado de su interrelación, sea cual fuere la naturaleza de ésta (37).

\section{Conclusiones}

El carácter cualitativo del estudio permitió describir e identificar, desde la perspectiva de los padres, la percepción que tienen respecto a las situaciones que afectan la salud y el bienestar de sus hijos adolescentes escolarizados, así como el concepto que tienen y los diferentes componentes de la salud.

Los diferentes discursos de los padres sobre el gran impacto que tiene la tecnología, la sexualidad, el bullying y las sustancias psicoactivas en la edad de la adolescencia nos proporcionan ciertas pautas para poder crear diferentes estrategias y así prevenir que los adolescentes caigan en estas situaciones, afectando su salud y su calidad de vida.

Durante la realización del estudio se destacó la importancia de estos estudios y de que enfermería los desarrolle pues permiten identificar situaciones de riesgo, ya sean reales o potenciales, que puedan afectar la calidad de vida relacionada con la salud y el bienestar. Esto traerá como consecuencia que se facilite entrar en contacto con los sujetos investigados.

Se identificó que son las madres quienes en un mayor porcentaje acuden a situaciones relacionadas con la escolaridad, la salud y el bienestar de sus hijos.

\section{Agradecimientos}

Agradecemos a las estudiantes Lisbeth Yaritza Gonzales Camargo y Jhoana Soledad Moreno Briñez por su colaboración en la organización de los grupos focales.

\section{Referencias}

1. Vélez CM, García García HI. Medición de la calidad de vida en niños. Iatreia. Universidad de Antioquia. 2012; 25(3): 240-249. Recuperado a partir de: http:// www.scielo.org.co/pdf/iat/v25n3/v25n3a07.pdf

2. Martínez Abreu J, Gispert Abreu EDLA. Consideraciones sobre el concepto de salud y su enfoque en relación a la salud bucal. Rev Méd Electrón [Internet]. 2014; 36(5): 671-680. Recuperado a partir de: http://scielo.sld.cu/pdf/rme/v36n5/rme150514.pdf

3. Agudelo-Londoño SM, Giraldo-Villa A, RomeroNieto V. Percepción del estado de salud en la región central colombiana: Encuesta Nacional de Salud. Rev. Salud Pública. 2012: 14 (6): 899-911. Recuperado a partir de: https://scielosp.org/pdf/rsap/v14n6/ v14n6a01.pdf

4. Reyes D, Gonzales E. Sexualidad, Salud y Sociedad: Elementos teóricos para el análisis del embarazo adolescente. Revista Latinoamericana. 2014; 17: 98-123. $\quad$ https://doi.org/10.1590/1984-6487. sess.2014.17.07.a

5. Gigliola Cannoni B., González MI. Sexualidad en la adolescente: Consejería. Revista Médica Clínica Los Condes. 2015; 26(1): 81-87. https://doi.org/10.1016/j. rmclc.2015.02.008

6. Hidalgo Rasmussen CA. Calidad de vida relacionada con la salud en adolescentes. En: Martinez, $\mathrm{R}$, editres. Salud y enfermedad del Niño y del Adolescente. Guadalajara: Manual Moderno; 2013. Recuperado a partir de: https://www.researchgate. net/publication $/ 270508943$ _Calidad_de_vida relacionada con la salud en adolescentes

7. Guedes DP, Astudillo HAV, Morales JMM, del Campo Vecino J, Pires Júnior R. Calidad de vida relacionada con la salud de adolescentes latinoamericanos. Rev Panam Salud Pública. 2014;35(1):46-52. Recuperado a partir de: https://scielosp.org/pdf/rpsp/v35n1/07.pdf

8. Higuita LF, Cardona JA. Instrumentos de evaluación de la calidad de vida relacionada con la salud del adolescente. Hacia promoc. salud. 2015; 20(2): $27-$ 42. Recuperado a partir de: http://www.scielo.org.co/ $\mathrm{pdf} / \mathrm{hpsal} / \mathrm{v} 20 \mathrm{n} 2 / \mathrm{v} 20 \mathrm{n} 2 \mathrm{a} 03 . \mathrm{pdf}$

9. Aymerich M., Berra S. Desarrollo de la versión en español de KIDSCREEN, un cuestionario de calidad de vida para la población infantil y adolescente. Gac 
Sanit. 2005; 19 (2). https://doi.org/10.1157/13074363

10. Vélez CM, Lugo LH. Validez y confiabilidad del 'Cuestionario de calidad de vida KIDSCREEN-27' versión padres, en Medellín, Colombia. Revista Colombiana de Psiquiatría. 2012; 41. https://doi. org/10.1016/S0034-7450(14)60031-7

11. Jasso Gutierrez L, López Ortega M. El impacto de los Determinantes Sociales de la Salud en los niños. Bol. Med.Hosp.Infant.Mex.2014;71(2).Recuperadoapartir de: $\quad$ http://www.scielo.org.mx/scielo.php?script=sci arttext\&pid=S1665-11462014000200009

12. Herranz Barrero A., López de Meza R. Percepción de padres e hijos de la calidad de vida relacionada con la salud de niños según el estado ponderal en Navarra, España. Arch. argent. pediatr. 2013; 111(6). https:// doi.org/10.5546/aap.2013.508

13. Escobar Cardona F., Acero Gonzales AR. Homicidas juveniles en Bogotá, estudio de grupos focales Rev. Fac. Med. 2015; 63(3): 389-98. https://doi. org/10.15446/revfacmed.v63n3.50632

14. Fernández López JA, Fernández Fidalgo M. Medición de la calidad de vida en niños y adolescentes: comprobación preliminar de la validez y fiabilidad de la versión española del cuestionario KINDL. Revista Atención Primaria. 2004; 33(8): 434-442. https://doi. org/10.1016/S0212-6567(04)79429-9

15. Rojas Reyes MJ, Gómez Restrepo C. Calidad de vida relacionada con salud en la población Colombiana: ¿cómo valoran los colombianos su estado de salud? Rev. salud pública [Internet]. 2017; 19(3), 340-346. https://doi.org/10.15446/rsap.v19n3.54226

16. Arroyo Cuesta A, Fadrique Millán LN. Motivo de consulta más frecuente del adolescente tardío en el servicio de urgencias del hospital universitario Río Hortega De Valladolid [Tesis]. [Valladolid]: Universidad de Valladolid, 20142015. Recuperado a partir de: https://uvadoc.uva.es/ bitstream/10324/11846/7/TFG-H309.pdf

17. Trujillo Guerrero TJ, Vásquez Cruz E, Córdova Soriano JA. Percepción de la funcionalidad familiar y el consumo de alcohol en adolescentes. Atención Familiar. 2016; 23(3): 100-103. https://doi. org/10.1016/j.af.2016.07.003

18. Luengo CharathMX, MillanKlusseT.Madres y padres de adolescentes urbanos: percepciones y expectativas de la atención en salud sexual y reproductiva para sus hijos. Rev. méd. Chile. 2014; 142 (10). https://doi. org/10.4067/S0034-98872014001000005

19. Buss Thofehrn M, López Montesinos MJ, Rutz Porto A, Coelho Amestoy S, Oliveira Arrieira IC, Marzena M. Grupo focal: una técnica de recogida de datos en investigaciones cualitativas. Index Enferm [Internet]. 2013 ; 22 (1-2): 75-78. https://doi.org/10.4321/S1132$\underline{12962013000100016}$
20. Martínez A, Ruiz J, Pérez S, Nieto J, Cmpoy J. La percepción del sobrepeso y la obesidad infantil por parte de los progenitores. Rev. Esp. Salud Publica. 2012; 86 (5). Recuperado a partir de: $\quad$ http://scielo.isciii.es/scielo.php?script=sci arttext\&pid $=$ S1135-57272012000500003

21. Méndez M., Aragón S. La Percepción De Los Padres Sobre La Crianza De Los Hijos. Act. Colom.Psicol. 2014; 17(2). Recuperado a partir de: $\quad$ http://www.scielo.org.co/scielo.php?script=sci arttext\&pid=S0123-91552014000200014

22. PizarroP, SantanaA, VialB.Laparticipación de la familiay su vinculación en los procesos de aprendizaje de los niños y niñas en contextos escolares. Diversitas: Perspectivas en Psicología. [Revista Internet] 2013; 9 (2), 271-287. https://doi.org/10.15332/s1794-9998.2013.0002.03

23. Ramírez W, Vinaccia S. El impacto de la actividad física y el deporte sobre la salud, la cognición, la socialización y el rendimiento académico: una revisión teórica. Rev.estud. soc. $2004 ; 18$. https://doi.org/10.7440/res18.2004.06

24. Lourdes I, Morales A. Espiritualidad y Religión: Percepciones de un Grupo de Adolescentes Puertorriqueños/as Sobre su Influencia en las Conductas de Riesgo de la Salud. Revista Ciencias de la Conducta. 2012. Recuperado a partir de: http://www.albizu. edu/Portals/0/Documents/cau/sju/Revista/2012/7 Religiosidad Conductas de Riesgo.pdf

25. Limones Silva I. Adolescentes y percepción del sí mismo: La construcción de una imagen realista de la adolescencia desde la familia y la escuela. Revista Ética Net. 2011; 11. Recuperado a partir de: http://www.ugr.es/ sevimeco/ revistaeticanet/numero11/Articulos/Formato/articulo11. pdf

26. Silva Diverio I. La adolescencia y su interrelación con el entorno. Madrid: Instituto de la Juventud; 2010. Recuperado a partir de: http://www.injuve.es/sites/ default/files/LA $\% 20$ ADOLESCENCIA $\% 20 \mathrm{y} \% 20 \% 20$ entorno completo.pdf

27. Lacave TT, Barrió TV, Barandalla LM. Percepción de los padres sobre el empoderamiento digital de las familias en hogares hiperconectados. El profesional de la información. 2017; 26(1): 97-104. https://doi. org/10.3145/epi.2017.ene.10

28. Menéndez Gonzales L, Orts Cortez MI. Factores psicosociales y conductuales en la regulación del peso: autorregulación, autoeficacia y locus control. Enfermería Clínica. 2018; 28(3): 156-161. https://doi.org/10.1016/j. enfcli.2018.02.005

29. Espitia Carrascal RE., Montes Rotela M. Influencia de la familia en el proceso educativo de los menores del barrio costa azul de Sincelejo (Colombia). Investigación y desarrollo. 2009; 17(1): 84-105. Recuperado a partir de: http://www.scielo.org.co/pdf/ indes/v17n1/v17n1a04.pdf 
30. Aguirre Guiza NC, Aldana Pinzón OB. Factores familiares de riesgo de consumo de sustancias psicoactivas en estudiantes de una institución media técnica de Colombia. Revista de Salud Pública. 2017; 19. https://doi.org/10.15446/rsap.v19n1.41785

31. García Vega E., Menendez Robledo E. Sexuality, contraception and unsafe sexual behavior in adolescents. International Journal of Psychological Research. 2012; 5(1): 79-87. https://doi. org/10.21500/20112084.764

32. Vanina Schmidt AM, Nadia Messoulam MF. La Comunicación del Adolescente con Sus Padres: Construcción y Validación de Una Escala desde un Enfoque Mixto. Revista Interamericana de Psicología. 2010; 44(2): 299-311. Recuperado a partir de: http:// www.redalyc.org/pdf/284/28420641011.pdf

33. Delgado Rodríguez RF, Pérez Marfil, MN (dir), Robles Ortega, H (dir). Relaciones interpersonales de la adolescencia: implementación de un programa de entrenamiento en asertividad y habilidades sociales para adolescentes de $1^{\circ}$ y $2^{\circ}$ de la ESO [Tesis]. [Granada]: Universidad de Granada; 2010. Recuperado a partir de: http://digibug.ugr.es/ handle/10481/5597

34. Barreto-Zorza YM, Velásquez-Gutiérrez VF. Funcionalidad familiar una percepción de madres e hijos escolares: Programa de atención primaria, Guapi-Cauca. MedUNAB [Internet]. 20 de marzo de 2016 [citado 24 de junio de 2021];18(3):166-73. doi: https://doi.org/10.29375/01237047.2363

35. Monsalve Londoño S. Vida saludable: actividades de ocio y recreación como aprovechamiento del tiempo libre en la población juvenil [Tesis]. [Medellín]: Universidad CES; 2016. Recuperado a partir de: https://repository.ces.edu.co/bitstream/10946/2770/1/ Vida Saludable.pdf

36. Oblitas LA. Emociones, salud y enfermedad. Universidad Nacional Autónoma de México. Revista Athenea. 2012. Recuperado a partir de: https:// rinconemocional.files.wordpress.com/2012/05/ emociones-salud-y-enfermedad.pdf

37. Molano-Tobar NJ, Velez-Tobar RA, Molano-Tobar DX. Correlación entre índice de masa corporal, circunferencia de cintura y riesgo cardiovascular en jóvenes escolares de Popayán, Colombia. MedUNAB [Internet]. 19 de junio de 2019 [citado 24 de junio de 2021];21(3):354-62. doi: https://doi. org/10.29375/01237047.2674

Anexo 1. Cuadro de codificación

Codigo

E1MG1P1

E3FG1P8

E3FG2P1

E3FG1P5

E4FG1P1

E2FG1P2

E3FG1P8

E2FG1P3

E5FG1P2

E1FG2P2

E2FG1P8

E3FG2P8

E4FG2P8

E2FG2P1

E4FG1P10

E3FG2P1

E1FG2P6

E1FG2P1

E4FG1P5

E4FG2P5

E2FG2P9

E2FG1P6

E4FG1P6

E4FG2P1

E5MG2P9

\section{Interpretación}

Entrevistado 1, Masculino, Grupo Focal 1, Pregunta 1

Entrevistado 3, Femenina, Grupo Focal 1, Pregunta 8

Entrevistado 3, Femenina, Grupo Focal 2, Pregunta 1

Entrevistado 3, Femenina, Grupo Focal 1 Pregunta 5

Entrevistado 4, Femenina, Grupo Focal 1 , Pregunta 1

Entrevistado 2, Femenina, Grupo Focal 1 , Pregunta 2

Entrevistado 3, Femenina, Grupo Focal 1, Pregunta 8

Entrevistado 2, Femenina, Grupo Focal 1 , Pregunta 3

Entrevistado 5, Femenina, Grupo Focal 1 , Pregunta 2

Entrevistado 1, Femenina, Grupo Focal 2, Pregunta 2

Entrevistado 2, Femenina, Grupo Focal 1, Pregunta 8

Entrevistado 3, Femenina, Grupo Focal 2, Pregunta 8

Entrevistado 4, Femenina, Grupo Focal 2, Pregunta 8

Entrevistado 2, Femenina, Grupo Focal 2, Pregunta 1

Entrevistado 4, Femenina, Grupo Focal 1, Pregunta 10

Entrevistado 3, Femenina, Grupo Focal 2, Pregunta 1

Entrevistado 1, Femenina, Grupo Focal 2, Pregunta 6

Entrevistado 1, Femenina, Grupo Focal 2, Pregunta 1

Entrevistado 4, Femenina, Grupo Focal 1, Pregunta 5

Entrevistado 4, Femenina, Grupo Focal 2, Pregunta 5

Entrevistado 2, Femenina, Grupo Focal 1, Pregunta 9

Entrevistado 2, Femenina, Grupo Focal 1 Pregunta 6

Entrevistado 4, Femenina, Grupo Focal 1, Pregunta 6

Entrevistado 4, Femenina, Grupo Focal 2, Pregunta 1

Entrevistado 5, Masculino, Grupo Focal 2, Pregunta 9 


\begin{tabular}{|c|c|c|c|}
\hline E4FG1P9 & $\begin{array}{c}\text { Entrevistado 4, Femenina, Grupo Focal } \\
\text { 1, Pregunta } 9\end{array}$ & E2FG2P9 & $\begin{array}{c}\text { Entrevistado } 2 \text {, Femenina, Grupo Focal } \\
\text { 2, Pregunta } 9\end{array}$ \\
\hline E2FG2P9 & $\begin{array}{c}\text { Entrevistado } 2 \text {, Femenina, Grupo Focal } \\
\text { 2, Pregunta } 9\end{array}$ & E4FG2P9 & $\begin{array}{c}\text { Entrevistado 4, Femenina, Grupo Focal } \\
\text { 2, Pregunta } 9\end{array}$ \\
\hline E3FG2P9 & $\begin{array}{c}\text { Entrevistado } 3 \text {, Femenina, Grupo Focal } \\
\text { 2, Pregunta } 9\end{array}$ & E3FG1P5 & $\begin{array}{c}\text { Entrevistado } 3 \text {, Femenina, Grupo Focal } \\
\text { 1, Pregunta } 5\end{array}$ \\
\hline E2FG2P8 & $\begin{array}{c}\text { Entrevistado } 2 \text {, Femenina, Grupo Focal } \\
\text { 2, Pregunta } 8\end{array}$ & E4FG1P7 & $\begin{array}{c}\text { Entrevistado 4, Femenina, Grupo Focal } \\
\text { 1, Pregunta } 7\end{array}$ \\
\hline E1MG1P8 & $\begin{array}{c}\text { Entrevistado 1, Masculino, Grupo Focal } \\
\text { 1, Pregunta } 8\end{array}$ & E5FG1P7 & $\begin{array}{c}\text { Entrevistado 5, Femenina, Grupo Focal } \\
\text { 1, Pregunta } 7\end{array}$ \\
\hline E2FG1P3 & $\begin{array}{c}\text { Entrevistado } 2 \text {, Femenina, Grupo Focal } \\
\text { 1, Pregunta } 3\end{array}$ & E3FG1P8 & $\begin{array}{c}\text { Entrevistado } 3 \text {, Femenina, Grupo Focal } \\
\text { 1, Pregunta } 8\end{array}$ \\
\hline E3FG1P3 & $\begin{array}{c}\text { Entrevistado } 3 \text {, Femenina, Grupo Focal } \\
\text { 1, Pregunta } 3\end{array}$ & E4FG1P10 & $\begin{array}{c}\text { Entrevistado 4, Femenina, Grupo Focal } \\
\text { 1, Pregunta } 10\end{array}$ \\
\hline E1FG1P3 & $\begin{array}{c}\text { Entrevistado 1, Femenina, Grupo Focal } \\
\text { 1, Pregunta } 3\end{array}$ & E4FG2P8 & $\begin{array}{c}\text { Entrevistado 4, Femenina, Grupo Focal } \\
\text { 2, Pregunta } 8\end{array}$ \\
\hline E4FG1P3 & $\begin{array}{c}\text { Entrevistado 4, Femenina, Grupo Focal } \\
\text { 1, Pregunta } 3\end{array}$ & E1MG1P1 & $\begin{array}{c}\text { Entrevistado 1, Femenina, Grupo Focal } \\
\text { 1, Pregunta } 1\end{array}$ \\
\hline E3FG1P3 & $\begin{array}{c}\text { Entrevistado } 3 \text {, Femenina, Grupo Focal } \\
\text { 1, Pregunta } 3\end{array}$ & E3FG2P8 & $\begin{array}{c}\text { Entrevistado } 3 \text {, Femenina, Grupo Focal } \\
\text { 2, Pregunta } 8\end{array}$ \\
\hline E5MG2P2 & $\begin{array}{c}\text { Entrevistado 5, Masculino, Grupo Focal } \\
\text { 2, Pregunta } 2\end{array}$ & E3FG1P8 & $\begin{array}{c}\text { Entrevistado } 3 \text {, Femenina, Grupo Focal } \\
\text { 1, Pregunta } 8\end{array}$ \\
\hline E4FG1P3 & $\begin{array}{c}\text { Entrevistado 4, Femenina, Grupo Focal } \\
\text { 1, Pregunta } 3\end{array}$ & E2FG1P8 & $\begin{array}{c}\text { Entrevistado } 2 \text {, Femenina, Grupo Focal } \\
\text { 1, Pregunta } 8\end{array}$ \\
\hline E1MG1P3 & $\begin{array}{c}\text { Entrevistado 1, Femenina, Grupo Focal } \\
\text { 1, Pregunta } 3\end{array}$ & E1FG2P6 & $\begin{array}{c}\text { Entrevistado 1, Femenina, Grupo Focal } \\
\text { 2, Pregunta } 6\end{array}$ \\
\hline E2FG2P3 & $\begin{array}{c}\text { Entrevistado } 2 \text {, Femenina, Grupo Focal } \\
\text { 2, Pregunta } 3\end{array}$ & E1FG2P1 & $\begin{array}{c}\text { Entrevistado 1, Femenina, Grupo Focal } \\
\text { 2, Pregunta } 1\end{array}$ \\
\hline E2FG2P3 & $\begin{array}{c}\text { Entrevistado } 2 \text {, Femenina, Grupo Focal } \\
\text { 2, Pregunta } 3\end{array}$ & E4FG1P3 & $\begin{array}{c}\text { Entrevistado 4, Femenina, Grupo Focal } \\
\text { 1, Pregunta } 3\end{array}$ \\
\hline E1FG2P3 & $\begin{array}{c}\text { Entrevistado 1, Femenina, Grupo Focal } \\
\text { 2, Pregunta } 3\end{array}$ & E3FG1P5 & $\begin{array}{c}\text { Entrevistado } 3 \text {, Femenina, Grupo Focal } \\
\text { 1, Pregunta } 5\end{array}$ \\
\hline E4FG1P3 & $\begin{array}{c}\text { Entrevistado 4, Femenina, Grupo Focal } \\
\text { 1, Pregunta } 3\end{array}$ & E4FG2P1 & $\begin{array}{c}\text { Entrevistado 4, Femenina, Grupo Focal } \\
\text { 2, Pregunta } 1\end{array}$ \\
\hline E3FG1P3 & $\begin{array}{c}\text { Entrevistado } 3 \text {, Femenina, Grupo Focal } \\
\text { 1, Pregunta } 3\end{array}$ & E4FG1P9 & $\begin{array}{c}\text { Entrevistado 4, Femenina, Grupo Focal } \\
\text { 1, Pregunta } 9\end{array}$ \\
\hline E1MG1P3 & $\begin{array}{c}\text { Entrevistado 1, Masculino, Grupo Focal } \\
\text { 1, Pregunta } 3\end{array}$ & \multirow{9}{*}{\multicolumn{2}{|c|}{ Fuente: elaboración propia. }} \\
\hline E4FG1P3 & $\begin{array}{c}\text { Entrevistado 4, Femenina, Grupo Focal } \\
\text { 1, Pregunta } 3\end{array}$ & & \\
\hline E3FG2P3 & $\begin{array}{c}\text { Entrevistado } 3 \text {, Femenina, Grupo Focal } \\
\text { 2, Pregunta } 3\end{array}$ & & \\
\hline E1FG2P3 & $\begin{array}{c}\text { Entrevistado } 1 \text {, Femenina, Grupo Focal } \\
\text { 2, Pregunta } 3\end{array}$ & & \\
\hline E3FG2P3 & $\begin{array}{c}\text { Entrevistado } 3 \text {, Femenina, Grupo Focal } \\
\text { 2, Pregunta } 3\end{array}$ & & \\
\hline E2FG2P3 & $\begin{array}{c}\text { Entrevistado 2, Femenina, Grupo Focal } \\
\text { 2, Pregunta } 3\end{array}$ & & \\
\hline E3FG1P5 & $\begin{array}{c}\text { Entrevistado } 3 \text {, Femenina, Grupo Focal } \\
\text { 1, Pregunta } 5\end{array}$ & & \\
\hline E1MG1P7 & $\begin{array}{c}\text { Entrevistado 1, Masculino, Grupo Focal } \\
\text { 1, Pregunta } 7\end{array}$ & & \\
\hline E2FG2P9 & $\begin{array}{c}\text { Entrevistado } 2 \text {, Femenina, Grupo Focal } \\
\text { 2, Pregunta } 9\end{array}$ & & \\
\hline
\end{tabular}

